\title{
Suplementação de lipídios em dietas para cabras em lactação: consumo e eficiência de utilização de nutrientes ${ }^{1}$
}

\section{Márcia Maria Cândido da Silva², Marcelo Teixeira Rodrigues ${ }^{3}$, Renata Helena Branco ${ }^{4}$, Carla Aparecida Florentino Rodrigues ${ }^{5}$, José Lindenberg Rocha Sarmento ${ }^{6}$, Augusto César de Queiroz $^{3}$, Simone Pedro da Silva ${ }^{7}$}

\author{
${ }^{1}$ Parte da tese de Doutorado da primeira autora apresentada à UFV-Viçosa, MG. \\ 2 Pós-doutoranda em Zootecnia - UFV. \\ ${ }^{3}$ Depto. de Zootecnia - UFV. \\ 4 IZ - Sertãozinho, SP \\ 5 Doutora em Zootecnia. \\ 6 UFPI. \\ 7 Graduação em Zootecnia - UFV, Viçosa-MG
}

RESUMO - O efeito de diferentes formas de suplementação lipídica sobre o consumo, a digestibilidade, o balanço de compostos nitrogenados, a produção de leite e a eficiência de utilização de nutrientes em cabras lactantes foi testado com a inclusão de óleo de soja (OS), sais de cálcio de ácidos graxos de cadeia longa (SC) e grão de soja (GS) na dieta. Foram utilizadas 24 cabras lactantes, alocadas em delineamento inteiramente casualizado, com quatro tratamentos e seis repetições. Os tratamentos consistiram de uma dieta controle (C), com 2,2\% de EE e isenta de lipídio suplementar, e de três outras dietas, adicionadas de um dos suplementos testados, contribuindo com 4,5\% de EE suplementar. O consumo voluntário e a produção de leite foram monitorados diariamente no período de 51 a 138 dias de lactação. Os consumos de MS (CMS), FDN (CFDN) e NDT (CNDT) e energia líquida (CEL) foram reduzidos com a suplementação com OS e GS. Os suplementos reduziram os coeficientes de digestibilidade da MO, PB e CT. O tratamento OS reduziu a digestibilidade da FDN e o GS, a digestibilidade dos CNF. O tratamento GS diminuiu as produções de leite e dos constituintes do leite (gordura e proteína). Os suplementos reduziram a produção de lactose, mas não influenciaram as concentrações dos constituintes do leite. Não foram observadas diferenças entre os valores de eficiência líquida de uso da EM consumida para produção de leite $\left(\mathrm{k}_{1}\right)$ obtidos nos tratamentos com adição de lipídios em relação à dieta controle. $\mathrm{O}$ balanço e a retenção de nitrogênio não foram afetados pela suplementação.

Palavras-chave: caprinos, leite, óleo, produção, sais de cálcio de ácidos graxos, soja

\section{Effects of fat supplements on intake and efficiency of nutrient utilization in lactating dairy goats}

\begin{abstract}
The effect of different fat supplements on intake, digestibility, nitrogen balance, milk yield and efficiency of nutrient utilization was evaluated in lactating dairy goats. Twenty-four dairy goats were assigned to a completely randomized design with four treatments and six replicates/treatment. The fat supplements tested were soybean oil (SO), calcium salts of longchain fatty acids (CS) and whole soybean (WS), which contributed with $4.5 \%$ of dietary ether extract. A control diet with no added fat was also fed to the animals. Daily measurements of intake and milk yield were done from day 51 to day 138 of lactation. Intakes of DM (DMI), NDF (NDFI), TDN (TDNI), and net energy (NEI) were lower on soybean oil and whole soybean than on control and CS diets. Feeding fat supplements to lactating goats reduced digestibilities of OM, CP and TC. Digestibility of NDF was reduced by SO while that of NFC was reduced by WS. Yields of milk fat, milk protein and milk decreased when WS was fed and the feeding of all three fat supplements depressed the yield of milk lactose. No significant differences in the concentration of milk components were observed across treatments. Similarly, the net efficiency of utilization of ingested metabolizable energy for milk production $(\mathrm{kl})$ did not differ among diets. The same was true for nitrogen balance and retained nitrogen.
\end{abstract}

Key Words: calcium salts of fatty acids, goats, milk, oil, production, soybean

\section{Introdução}

A produção de leite é um processo metabólico altamente dependente de energia. No início da lactação, ocorrem simultaneamente redução da capacidade de ingestão de MS e elevação das exigências energéticas, em razão da maior produção. Assim, os animais, por meio da homeorresia (Bauman, 2000), mobilizam suas reservas corporais para atender esta condição fisiológica. 
Os lipídios são considerados fontes energéticas com alta concentração de energia prontamente disponível, pois são constituídos de grande proporção de ácidos graxos, os quais possuem 2,25 vezes mais energia que os carboidratos. Suplementos lipídicos têm sido usados em dietas para animais lactantes com os objetivos de aumentar a produção de leite e reduzir a mobilização corpórea.

À exceção dos grãos, a maioria dos alimentos utilizados no arraçoamento de ruminantes contém baixas proporções de lipídios, com valores que variam de 1 a $4 \%$ da MS (Van Soest, 1994). Palmquist \& Jenkins (1980) sugeriram que a inclusão dos lipídios em dietas para ruminantes seja limitada em até 5\% da MS total, visto que os microrganismos ruminais não possuem mecanismos fisiológicos para digeri-los tão eficientemente como o fazem para os carboidratos e as proteínas.

Essa ineficiência microbiana para utilização dos lipídios como fonte de crescimento desencadeia uma série de alterações no ambiente ruminal. Um dos principais efeitos deletérios da inclusão de elevadas concentrações de lipídios é a redução na digestão ruminal da fibra (Ikwuegbu \& Sutton, 1982; Wettstein et al., 2000). Desse modo, as quantidades e as proporções de ácidos graxos voláteis produzidos no rúmen podem ser negativamente alteradas, especialmente a relação acetato:propionato (Chalupa et al., 1986; Doreau et al., 1990), promovendo a diminuição das produções de leite e de gordura no leite. Essas respostas, no entanto, não devem ser generalizadas, pois estão intimamente relacionadas à forma de inclusão dos lipídios nas dietas, ao grau de sua insaturação e ao comprimento da cadeia.

Para minimizar estes efeitos, tem-se sugerido o uso de gorduras ruminalmente inertes. Nos primeiros trabalhos com lipídios inertes, foi utilizada matriz protéica tratada com formaldeído. Posteriormente, o uso de gordura animal também foi proposto como alternativa para aumentar a concentração energética das dietas, sem afetar a fermentação ruminal, apresentando, no entanto, maior grau de saturação, que implica menor absorção intestinal. Atualmente, o termo gordura inerte foi substituído por gordura protegida e, neste grupo, encontram-se os sais de cálcio de ácidos graxos, que têm sido mais amplamente estudados e utilizados em rebanhos leiteiros. Esses sais (ou sabões) são obtidos pela reação de íons de cálcio com ácidos graxos de cadeia longa (insaturados e saturados), cujo princípio baseia-se na passagem deste complexo pelo rúmen e na sua dissociação nas condições ácidas do abomaso, tornando-os disponíveis para digestão e absorção.

Nesse contexto, é necessária a busca por outras fontes lipídicas que possam ser facilmente manipuladas visando ao melhor aporte energético para o animal, sem comprometer o ambiente ruminal.

O Brasil é o segundo maior produtor mundial de soja (em torno de 50 milhões de toneladas de grãos) e, de acordo com Moreira (1999), a maioria dos cultivares de soja apresenta de 15 a $25 \%$ de lipídios. No aspecto da nutrição de ruminantes, a soja grão pode ser considerada suplemento lipídico parcialmente protegido da hidrogenação ruminal, visto que as gotículas de lipídios em sementes oleaginosas se encontram inseridas na matriz protéica dos grãos, conferindo-lhes proteção natural.

Várias pesquisas têm sido desenvolvidas com lipídios (protegidos ou não) em dietas de vacas lactantes, mas, em caprinos, os estudos ainda são incipientes. Chilliard et al. (2003) sugeriram que o metabolismo mamário dessa espécie é diferenciado e, portanto, as respostas à suplementação lipídica podem ser distintas daquelas apresentadas por bovinos.

Desta forma, objetivou-se avaliar a adição de lipídios, em diferentes formas de proteção à hidrogenação ruminal, em dieta para cabras e verificar sua influência sobre o consumo, a digestibilidade dos nutrientes, o comportamento alimentar, o balanço dos compostos nitrogenados e as possíveis alterações na resposta animal, avaliadas pela produção de leite e de seus constituintes.

\section{Material e Métodos}

Este experimento foi conduzido no Setor de Caprinocultura do Departamento de Zootecnia da Universidade Federal de Viçosa, entre maio e agosto de 2004.

Foram utilizadas 24 cabras lactantes com $56,6 \pm 5,7 \mathrm{~kg}$, 28 dias em produção e produção média de leite de $2,6 \pm 0,52 \mathrm{~kg} / \mathrm{dia}$. Os animais foram confinados em baias individuais $\left(3 \mathrm{~m}^{2}\right)$ com piso ripado, adaptadas para coleta total de fezes e urina.

O delineamento experimental utilizado foi o inteiramente casualizado, em um total de quatro tratamentos (dietas) e seis repetições. Os tratamentos consistiram de uma dieta controle (C), isenta de lipídio suplementar, e de três dietas-teste, com diferentes suplementos lipídicos, selecionados de acordo com o grau de proteção à hidrogenação ruminal: óleo de soja (OS), não-protegido; sais de cálcio de ácidos graxos de cadeia longa $\left(\mathrm{SC}=\right.$ Megalac $^{\circledR} \mathrm{E}-$ Church \& Dwight, Co. $)$, protegido; e grão de soja (GS), parcialmente protegido.

As dietas foram compostas de feno de capim-tifton 85 (Cynodon spp.) como volumoso e mistura concentrada, à base de fubá de milho (Zea mays L.) e farelo de soja (Glycine $\max \mathrm{L}$.), complementada com mistura mineral e 
balanceada para atender às exigências nutricionais de cabras em lactação (AFRC, 1993; NRC, 1981). Na dieta GS, o grão de soja participou como principal fonte protéica, substituindo o farelo de soja.

A proporção dos ingredientes nas dietas e a composição dos alimentos e das dietas encontram-se nas Tabelas $1 \mathrm{e} 2$, respectivamente. As dietas utilizadas foram formuladas de modo que a razão energia metabolizável fermentável/ proteína bruta (EMF/PB) e o nível de EE no suplemento fossem mantidos constantes.

O período experimental compreendeu uma fase préexperimental ( 23 dias) e uma fase de coleta de dados ( 86 dias) na qual foram avaliados o consumo e a produção de leite dos animais.

As dietas foram fornecidas duas vezes ao dia, às $8 \mathrm{~h} 30$ e $16 \mathrm{~h} 30$, permitindo-se $10 \%$ de sobras. Elaboraram-se amostras compostas de sobras por animal referentes a períodos experimentais de 28 dias, que foram congeladas para posteriores análises.

Os animais foram pesados no início e final do período experimental e a intervalos de 21 dias. As cabras foram ordenhadas manualmente às 6 e $15 \mathrm{~h}$, efetuando-se o controle leiteiro individual no momento da ordenha, mediante a pesagem do leite.

Os dados de consumo de MS foram comparados aos valores estimados pelo AFRC (1993), utilizando-se na equação proposta as médias de peso e de produções de leite obtidas no experimento: $\mathrm{CMS}(\mathrm{kg} / \mathrm{d})=0,062 * \mathrm{PV}^{0,75}+$ $0,305 *$ Produção de leite

Quinzenalmente, o leite era amostrado proporcionalmente às coletas da tarde e da manhã do dia seguinte, acondicionado em tubos próprios contendo conservante Bronopol ${ }^{\circledR}$ (2-bromo-2-nitropropano-1,3-diol) e encaminhado ao Laboratório de Qualidade do Leite da Embrapa Gado de Leite, para determinação dos teores de PB, lactose e gordura em equipamento Bentley Combi 2003.

Para estimativa dos coeficientes de digestibilidade aparente da MS e dos nutrientes e determinação do balanço de nitrogênio, utilizou-se o método de coleta total de fezes e urina durante cinco dias consecutivos em cada unidade experimental. Nesse período, amostras das sobras foram obtidas diariamente, constituindo uma amostra composta ao final do quinto dia. Os animais foram pesados no primeiro e no último dia da semana da coleta. A urina foi coletada em recipientes plásticos contendo $20 \mathrm{~mL}$ de solução de $\mathrm{H}_{2} \mathrm{SO}_{4}$ $40 \%(\mathrm{v} / \mathrm{v})$. Fezes e urina, depois de coletadas e pesadas, foram amostradas em alíquotas de $10 \%$ e congeladas para posteriores análises laboratoriais.

No cálculo do balanço de nitrogênio, consideraram-se as quantidades de nitrogênio ( $\mathrm{g} / \mathrm{dia}$ ) consumidas e
Tabela 1 - Proporções, expressas na matéria seca, dos ingredientes nas dietas experimentais

Table 1 - Ingredient composition of the experimental diets, \% of DM

\begin{tabular}{|c|c|c|c|c|}
\hline \multirow[t]{3}{*}{$\begin{array}{l}\text { Ingrediente } \\
\text { Ingredient }\end{array}$} & \multicolumn{4}{|c|}{$\begin{array}{l}\text { Dieta } \\
\text { Diet }\end{array}$} \\
\hline & $\mathrm{C}$ & OS & $\mathrm{SC}$ & GS \\
\hline & C & SO & $C S$ & $W S$ \\
\hline & \multicolumn{4}{|c|}{$\% \operatorname{MS}(\% D M)$} \\
\hline $\begin{array}{l}\text { Feno de capim-tifton } 85 \\
\text { Tifton hay }\end{array}$ & 40,84 & 40,84 & 40,84 & 40,84 \\
\hline $\begin{array}{l}\text { Fubá de milho } \\
\text { Ground corn }\end{array}$ & 37,15 & 34,05 & 33,69 & 35,04 \\
\hline $\begin{array}{l}\text { Farelo de soja } \\
\text { Soybean meal }\end{array}$ & 20,31 & 18,95 & 18,80 & - \\
\hline $\begin{array}{l}\text { Grão de soja } \\
\text { Whole soybean }\end{array}$ & - & - & - & 22,42 \\
\hline $\begin{array}{l}\text { Óleo de soja } \\
\text { Soybean oil }\end{array}$ & - & 4,50 & - & - \\
\hline $\begin{array}{l}\text { Megalac- } E^{\circledR} \\
\text { Megalac- } E^{\circledR}\end{array}$ & - & - & 5,05 & - \\
\hline $\begin{array}{l}\text { Calcário } \\
\text { Limestone }\end{array}$ & 0,37 & 0,37 & 0,37 & 0,37 \\
\hline $\begin{array}{l}\text { Fosfato bicálcico } \\
\text { Dicalcium phosphate }\end{array}$ & 0,73 & 0,73 & 0,73 & 0,73 \\
\hline $\begin{array}{l}\text { Mistura mineral* } \\
\text { Mineral mixture }\end{array}$ & 0,59 & 0,59 & 0,59 & 0,59 \\
\hline
\end{tabular}

* Mistura mineral: $0,32 \%$ de sulfato ferroso; $0,48 \%$ de sulfato de cobre; $0,71 \%$ de sulfato de manganês; $2,67 \%$ de sulfato de zinco; $0,02 \%$ de sulfato de cobalto; $0,0125 \%$ de iodato de potássio; $0,006 \%$ de selenito de sódio; $95,78 \%$ de cloreto de sódio.

$\mathrm{C}=$ controle; OS = óleo de soja; $\mathrm{SC}$ = sais de cálcio; $\mathrm{GS}$ = grão de soja * Mineral mix: $0.32 \%$ of iron sulfate, $0.48 \%$ of copper sulfate; $0.71 \%$ of manganese sulfate,

$2.67 \%$ of zinc sulfate, $0.02 \%$ of cobalt sulfate, $0.0125 \%$ of potassium iodate, $0.006 \%$ of

sodium selenite, $95.78 \%$ of sodium chloride.

$C=$ control; $S O=$ soybean oil; $C S=$ calcium salts; $W S=$ whole soybean

excretadas nas fezes, na urina e no leite. O conteúdo de nitrogênio do leite foi obtido dividindo-se o valor de PB do leite obtido durante a semana em que se fez o estudo da digestibilidade pelo fator de conversão 6,38 (McDonald, 1993).

A partir destes valores, procedeu-se ao cálculo para quantificação do nitrogênio retido (NRet), descontando-se do BN o valor estimado da exigência para nitrogênio endógeno basal (NEB), de acordo com o AFRC (1993), que considera o $\mathrm{N}$ endógeno tecidual e as perdas dérmicas de $\mathrm{N}$ como 0,35 e 0,018 do peso metabólico, respectivamente.

Os alimentos, as sobras e as fezes foram analisados quanto aos teores de MS, nitrogênio total (NT), EE e cinzas, utilizando-se as técnicas descritas por Silva \& Queiroz (2002), e de FDN e FDA, segundo Van Soest et al. (1991). Nos alimentos, procedeu-se também às análises de nitrogênio insolúvel em detergente neutro (NIDN) e nitrogênio insolúvel em detergente ácido (NIDA), de acordo com técnicas descritas por Licitra et al. (1996), e de lignina em detergente ácido (LDA), conforme descrito por Pereira \& Rossi Jr. (1995). Nas amostras de urina, foram determinados os percentuais de NT. 
Tabela 2 - Composição bromatológica dos alimentos e das dietas experimentais

Table 2 - Chemical composition of feeds and experimental diets

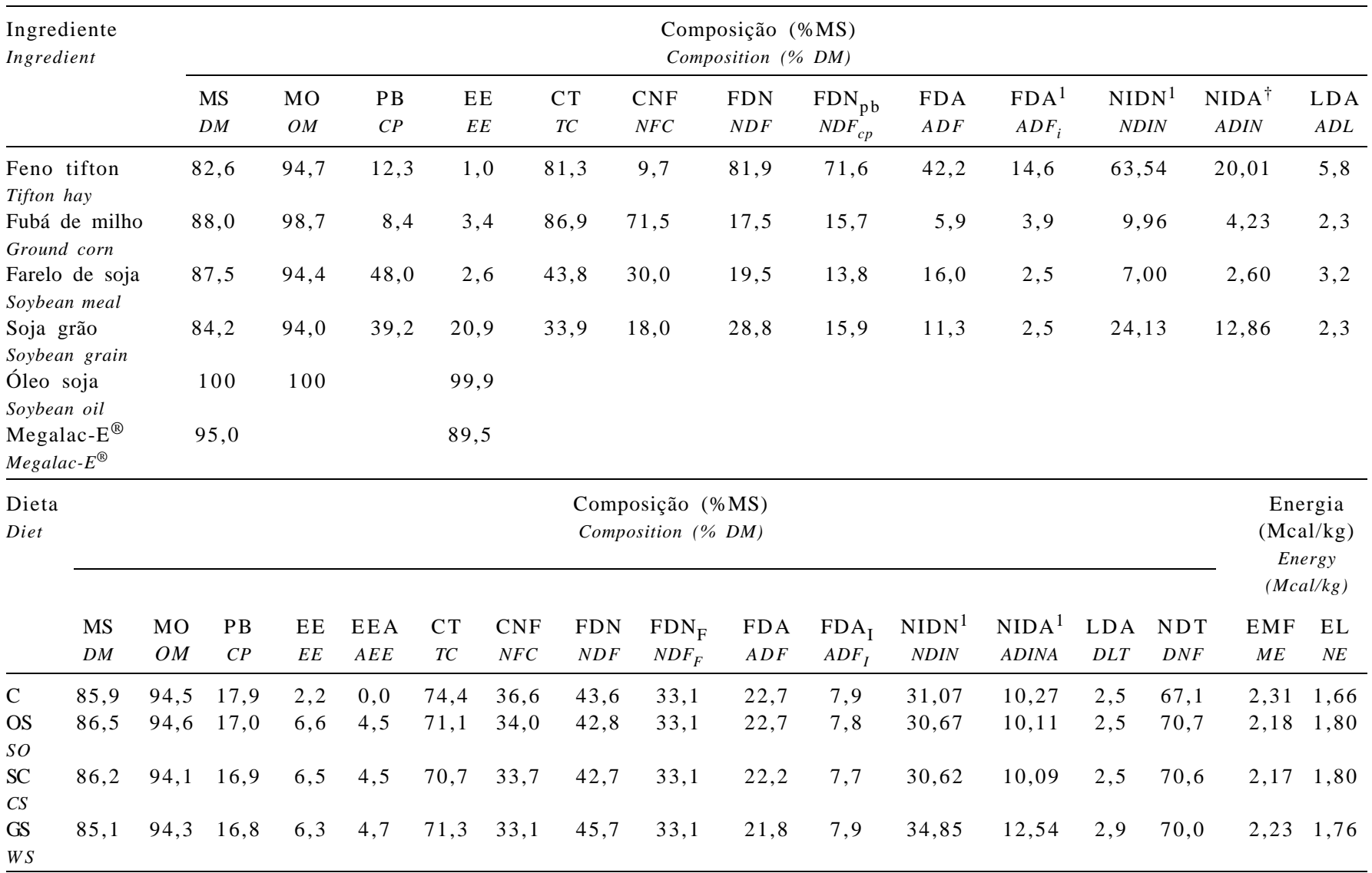

$\mathrm{C}=$ controle; $\mathrm{OS}=$ óleo de soja; $\mathrm{SC}$ = sais de cálcio; $\mathrm{GS}$ = grão de soja.

$1 \%$ do nitrogênio total (\% of total nitrogen).

$\mathrm{EEA}$ = extrato etéreo adicional; LDA = lignina em detergente ácido; EMF = energia metabolizável fermentável.

$C=$ control $: S O=$ soybean oil $; C S=$ calcium salts $; W S=$ whole soybean .

$A E E=$ added ether extract; $A D L=$ acid detergent lignin; $F M E=$ fermentable metabolizable energy.

Os CT e CNF foram obtidos a partir das equações propostas por Sniffen et al. (1992) e Van Soest et al. (1991), respectivamente:

$$
\begin{gathered}
\mathrm{CT}=100-(\% \mathrm{~PB}+\% \mathrm{EE}+\% \text { Cinzas }), \\
\mathrm{CNF}=100-(\% \mathrm{~PB}+\% \mathrm{EE}+\% \text { Cinzas }+\% \mathrm{FDNcp})
\end{gathered}
$$

Os valores de energia dos ingredientes das dietas foram estimados pelas equações propostas pelo NRC (2001): $\mathrm{NDT}=\left(\mathrm{PB}_{\mathrm{D}}+\mathrm{CNF}_{\mathrm{D}}+\mathrm{FDN}_{\mathrm{D}}+\mathrm{AG}_{\mathrm{D}} \times 2,25\right)-7$, considerando-se a classe do alimento como volumoso, concentrado, produto de origem animal, ácido graxo ou triglicerídeo e o nível de alimentação (L) de 2,10, estimado durante o período préexperimental, conforme a fórmula a seguir:

$$
\mathrm{L}=\frac{\text { Exigência total de energia líquida }}{\text { Energia líquida de mantença }}
$$

Os valores de NDT foram convertidos em energia digestível (ED) e energia metabolizável (EM) utilizando-se as equações sugeridas pelo NRC (2001):

$\mathrm{EM}(\mathrm{Mcal} / \mathrm{kg})=1,01 * \mathrm{ED}(\mathrm{Mcal} / \mathrm{kg})-0,45$;

$$
\mathrm{ED}(\mathrm{Mcal} / \mathrm{kg})=0,04409 * \operatorname{NDT}(\%)
$$

Para a conversão do NDT em energia líquida, adotou-se a equação de Moe et al. (1972), que corresponde à energia líquida no nível de mantença, $\mathrm{EL}_{\mathrm{L}}(\mathrm{Mcal} / \mathrm{kg})=0,0266 * \mathrm{NDT}(\%)-0,12$, sendo o resultado reduzido em 4,4\% para o nível de alimentação calculado (2,1 x) como proposto por Moe \& Tyrrell (1977), que sugeriram redução de $4 \%$ na digestibilidade por múltiplo do nível de mantença.

Para o cálculo da energia metabolizável fermentável (EMF), deduziu-se da EM o valor de 1,4 (MJ/kg) ou 0,3346 (Mcal/kg), como descrito pelo AFRC (1993). O cálculo da estimativa da EMF é necessário, pois os lipídios não são fontes de energia para os microrganismos. Assim, para os suplementos lipídicos óleo e Megalac- $\mathrm{E}^{\circledR}$, o valor de EMF foi considerado zero, enquanto, para o grão de soja, o valor de NDT foi calculado como se o grão tivesse $0 \%$ de EE. Para a quantificação das rações, foram utilizados os valores da digestibilidade aparente obtidos no experimento.

A estimativa da eficiência líquida de utilização da energia metabolizável para a produção de leite $\left(\mathrm{k}_{1}\right)$ foi feita 
calculando-se a razão entre o valor de energia do leite produzido e o consumo de energia metabolizável total subtraído do consumo de energia para a mantença:

$$
\mathrm{k}_{1}=\frac{\mathrm{ELp}}{\mathrm{CEMp}-\mathrm{m}}
$$

A estimativa da eficiência bruta de utilização da energia metabolizável para a produção de leite $\left(\mathrm{k}_{\mathrm{m}+\mathrm{p}}\right)$ foi feita calculando-se a razão entre a exigência líquida para a produção de leite e o consumo de energia metabolizável total $\left(\mathrm{CEM}_{\mathrm{p}}\right)$, segundo Luo et al. (2004):

$$
\mathrm{k}_{\mathrm{m}+\mathrm{p}}=\frac{\mathrm{CELm}+\mathrm{ELp}}{\mathrm{CEM}}
$$

Os dados obtidos foram analisados pelo procedimento GLM do programa computacional Statistical Analysis System (SAS, 1999), aplicando-se o teste Student-NewmanKeuls (SNK) a de 5\% de probabilidade para comparação das médias.

\section{Resultados e Discussão}

Os dados referentes ao consumo voluntário de MS e nutrientes encontram-se na Tabela 3.

Os suplementos lipídicos afetaram significativamente o consumo de todos os nutrientes estudados. Os tratamentos OS e GS resultaram em reduções de 14,9 e 18,2\%, respectivamente, no consumo de MS $(\mathrm{kg} / \mathrm{d})$, enquanto o tratamento SC não promoveu variação no consumo de MS, o que pode ser atribuído à palatabilidade dessas dietas, visto que, durante o experimento, verificou-se rejeição ao grão de soja por alguns animais.

Outra possível explicação para a redução do consumo no tratamento com óleo de soja está relacionada à teoria de regulação do consumo, proposta por Nicholson \& Omer (1983), que sugeriram que aumento da secreção de colecistoquinina (CCK), decorrente da presença de ácidos graxos insaturados (AGI) na digesta, pode inibir a motilidade no rúmen e retículo, reduzindo o consumo de alimentos.

A adição de sais de cálcio não afetou o consumo de MS em relação ao tratamento controle. Os dados da literatura não são conclusivos quanto aos efeitos do fornecimento de SC no consumo de nutrientes. Allen (2000) desenvolveu equações envolvendo 24 estudos sobre o fornecimento de SC e sugeriu que a adição de $1 \%$ de SC reduz em 2,5\% o consumo de MS. Outros autores (Scheneider et al., 1988; Palmquist, 1991; Perez Alba et al., 1997) não encontraram efeito da suplementação com SC no consumo de MS em vacas e ovinos.

Embora a proporção em ácidos graxos insaturados na formulação do SC comercial usado neste experimento (Megalac ${ }^{\circledR}$-E) seja mais elevada que nas formulações mais antigas, a participação em ácidos graxos saturados nesse suplemento é relativamente elevada se comparada à do óleo de soja (Siva, 2005). Portanto, provavelmente o mecanismo de regulação fisiológica seja o mais adequado para justificar os mais altos consumos da dieta com SC em comparação aos outros suplementos.

As estimativas de consumo de MS apresentadas pelo AFRC (1993), que utiliza o peso e a produção de leite como variáveis, têm sido referenciadas como adequado indicador desse comportamento animal. Com a utilização dessa fórmula para estimativa do consumo nos tratamentos controle, OS, SC e GS, respectivamente, obtêm-se valores de 1,$90 ; 1,88 ; 1,84$ e $1,76 \mathrm{~kg} / \mathrm{d}$. Os valores de consumo observados neste experimento (Tabela 3), no entanto, representaram $95,82,98$ e $84 \%$ do consumo estimado. Desse modo, verifica-se que as dietas controle e com SC foram eficientes em manter o consumo quando comparados seus valores aos estimados pelo AFRC (1993).

Tabela 3 - Efeito da suplementação lipídica sobre o consumo de MS e de nutrientes por cabras em lactação

\begin{tabular}{|c|c|c|c|c|c|}
\hline \multirow[t]{3}{*}{$\begin{array}{l}\text { Item } \\
\text { Item }\end{array}$} & \multicolumn{4}{|c|}{$\begin{array}{c}\text { Dieta } \\
\text { Diet }\end{array}$} & \multirow[t]{3}{*}{$\mathrm{CV}$} \\
\hline & $\mathrm{C}$ & OS & SC & GS & \\
\hline & $C$ & SO & $C S$ & $W S$ & \\
\hline CMS $(\mathrm{kg} / \mathrm{d})^{1}(D M I, k g / d)$ & $1,81^{\mathrm{a}}$ & $1,54^{\mathrm{b}}$ & $1,80^{\mathrm{a}}$ & $1,48^{b}$ & 13,90 \\
\hline CMS (\%PV) (DMI, \%BW) & $3,41^{\mathrm{a}}$ & $2,57^{\mathrm{b}}$ & $3,26^{\mathrm{a}}$ & $2,56^{\mathrm{b}}$ & 17,39 \\
\hline CFDN $(\mathrm{kg} / \mathrm{d})^{2}(N D F I, k g / d)$ & $708,66^{\mathrm{a}}$ & $587,04^{\mathrm{b}}$ & $701,57^{\mathrm{a}}$ & $649,78^{a b}$ & 14,85 \\
\hline CFDN (\%PV) (NDFI, \%BW) & $1,37^{\mathrm{a}}$ & $0,98^{\mathrm{b}}$ & $1,27^{\mathrm{a}}$ & $1,13^{\mathrm{ab}}$ & 18,12 \\
\hline $\mathrm{CCNF}(\mathrm{kg} / \mathrm{d})^{3}(N F C I, \mathrm{~kg} / \mathrm{d})$ & $739,61^{\mathrm{a}}$ & $586,10^{\mathrm{cb}}$ & $661,08^{a b}$ & $509,56^{\mathrm{c}}$ & 14,32 \\
\hline $\operatorname{CEE}(\mathrm{g} / \mathrm{d})^{4}(E E I, g / d)$ & $41,69^{\mathrm{c}}$ & $110,85^{b}$ & $129,30^{\mathrm{a}}$ & $103,81^{\mathrm{b}}$ & 12,62 \\
\hline
\end{tabular}
Table 3 - Effect of fat supplements on nutrient intake in lactating dairy goats

Médias na linha seguidas de letras distintas diferem a $5 \%$ de probabilidade pelo teste SNK.

$\mathrm{C}=$ controle; $\mathrm{OS}$ = óleo de soja; $\mathrm{SC}$ = sais de cálcio; $\mathrm{GS}$ = grão de soja.

${ }^{1}$ Consumo de MS; ${ }^{2}$ Consumo de FDN; ${ }^{3}$ Consumo de CNF; ${ }^{4}$ Consumo de EE; ${ }^{5}$ Consumo de NDT; ${ }^{6}$ Consumo de EL.

Means in a row followed by different letters differ at $5 \%$ of probability by SNK test.

$C=$ control; $S O=$ soybean oil; $C S=$ calcium salts; $W S=$ whole soybean .

${ }^{1} \mathrm{DM}$ intake; ${ }^{2} \mathrm{NDF}$ intake $;{ }^{3} \mathrm{NFC}$ intake $;{ }^{4} \mathrm{EE}$ intake $;{ }^{5} \mathrm{TDN}$ intake $;{ }^{6} \mathrm{NE}$ intake. 
Os tratamentos contendo óleo e grão de soja resultaram em valores de consumo de fibra semelhantes, no entanto, apenas a dieta contendo óleo de soja promoveu redução de $17 \%$ em relação à dieta controle, o que reforça a suposição de que a palatabilidade da ração foi fator determinante neste comportamento.

No caso de suplementação com grão de soja, deve-se salientar que sua maior concentração de fibra contribuiu para a ausência de diferenças em relação à dieta controle. A adição de SC não afetou o consumo de fibra pelos animais.

A concentração de FDN das rações (38 a 44\%), em relação à das dietas estabelecidas (42-46\%), está dentro de uma variação biológica de 5 a $10 \%$, que indica uma precisão adequada para experimentos desta natureza.

As dietas foram calculadas de modo que a fibra não fosse fator limitante ao consumo. É possível que a redução no consumo de fibra com a adição do óleo de soja seja reflexo do consumo de MS. Os consumos médios de fibra nas rações contendo óleo e grão ( $1,05 \%$ do peso do animal $)$ foram inferiores aos encontrados por Carvalho et al. (2006) e Branco (2005), que não verificaram efeitos de repleção ruminal com consumos médios de fibra de 1,53 e 1,24\% do peso do animal, respectivamente.

Os suplementos lipídicos reduziram o consumo de CNF (g/d) pelos animais, o que era esperado, pois este componente dietético foi substituído pelo EE suplementar. No entanto, os valores da concentração dos carboidratos CNF entre os tratamentos (34 a 40\%) mantiveram-se próximos da faixa recomendada por Hall (1999), que sugeriu níveis máximos de 35 e $45 \%$ de $\mathrm{CNF}$ nas dietas para evitar distúrbios metabólicos como a acidose ruminal.

A adição de lipídios favoreceu o maior consumo de EE (g/d) nas dietas suplementadas, sendo mais expressivo naquela contendo $\mathrm{SC}$.
De modo geral, a redução no consumo caracterizou a resposta dos animais aos alimentos disponíveis, sugerindo que a presença do óleo e do grão de soja na dieta reduz o consumo por cabras em lactação.

Este efeito hipofágico, decorrente da adição de óleo ou de grão, pode estar associado a alguns fatores envolvidos na regulação do consumo por ruminantes. De acordo com Allen (2000), os mecanismos pelos quais a suplementação lipídica reduz o consumo, embora não estejam bem elucidados, envolvem efeitos na fermentação ruminal, na motilidade intestinal, na palatabilidade das dietas, na liberação de hormônios intestinais e na oxidação da gordura no fígado.

Outras considerações podem ser sugeridas com base nos valores da Tabela 3. Considerando os menores consumos de MS e EE nas rações com óleo e grão de soja, é provável que tenha ocorrido algum efeito deletério sobre a fermentação ruminal, pois o óleo de soja apresenta maior proporção em ácidos graxos insaturados. Chelikàni et al. (2004) afirmaram que, quando ruminantes são alimentados com grandes quantidades de gorduras insaturadas, o consumo de alimentos é reduzido, e consideram os mesmos efeitos hipofágicos citados por Allen (2000).

Como demonstrado na Tabela 4, a suplementação lipídica não alterou a digestibilidade da MS (média de $74,55 \%$ ), mas influenciou os coeficientes de digestibilidade dos nutrientes.

Os coeficientes de digestibilidade da MO foram reduzidos pela suplementação lipídica (Tabela 4). Maior coeficiente de digestibilidade da PB $(84,21 \%)$ foi obtido na dieta controle em relação aos tratamentos com suplementos $(77,69 \%)$, e menor digestibilidade da FDN foi observada na dieta OS. Comportamento semelhante ao da PB foi observado para a digestibilidade dos CT, que foi reduzida com a adição

Tabela 4 - Efeito da suplementação lipídica sobre os coeficientes de digestibilidade da MS e de nutrientes de cabras em lactação Table 4 - Effect of fat supplements on digestibility of nutrients in lactating dairy goats

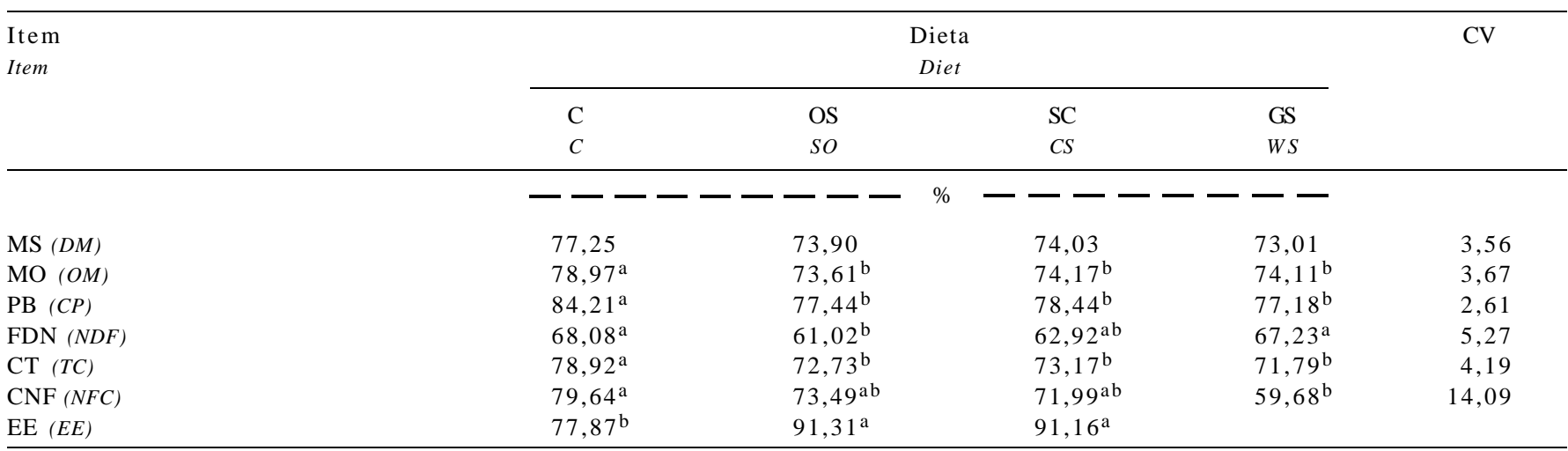

Médias na linha seguidas de letras distintas diferem a $5 \%$ de probabilidade pelo teste SNK

$\mathrm{C}=$ controle; OS = óleo de soja; $\mathrm{SC}$ = sais de cálcio; GS = grão de soja.

Means in a row followed by different letters differ at $5 \%$ of probability by SNK test.

$C=$ control; $S O=$ soybean oil $; C S=$ calcium salts; $W S=$ whole soybean 
de lipídios, com média de 78,9\% para controle e de 72,6\% para os demais tratamentos. A digestibilidade dos CNF foi reduzida apenas no tratamento com grão de soja, não sendo observada diferença entre a dieta controle e aquelas com suplementação, ao passo que os coeficientes de digestibilidade do EE nos tratamentos com suplementação foram mais altos que na dieta controle.

De acordo com Jenkins \& Jenny (1989), a adição de suplementos lipídicos diminui ou tem efeito mínimo sobre a digestibilidade da MS, apresentando raros efeitos de aumento. Bateman II \& Jenkins (1998) não constataram efeitos da inclusão de até $8 \%$ de óleo de soja sobre a digestibilidade aparente de MS, MO, N e FDN e sugeriram que grandes quantidades de lipídios não protegidos podem ser adicionadas a dietas, pois não provocam efeitos na digestibilidade.

A redução na digestibilidade aparente da MO sugere a ocorrência de alterações no ambiente ruminal pela suplementação lipídica, como relatado por Enjalbert et al. (1994), que observaram redução nas digestibilidades da MO com a utilização de diferentes formas de ácidos graxos poliinsaturados na dieta de ovinos.

Enjalbert et al. (1994) afirmaram que, independentemente da forma de suplementação lipídica, os ácidos graxos parecem não influenciar a digestibilidade aparente da PB. Possivelmente, a inclusão de óleo aumentou o escape da proteína dietética, promovendo maior participação de nitrogênio alimentar no material fecal e reduzindo o coeficiente de digestibilidade aparente da proteína. Em experimento realizado com cabras fistuladas (Silva, 2005), foram observadas reduções na concentração de amônia ruminal, que podem estar associadas à redução da atividade proteolítica dos protozoários pelo fato de os óleos serem agentes defaunadores.

Os valores mais altos de digestibilidade da fibra com a utilização do grão de soja, em comparação ao óleo de soja, podem ser decorrentes da presença da fibra na semente, considerada de mais fácil digestão que a fibra das forrageiras. É possível também que a lenta liberação de óleo na digesta ruminal com a adição do grão de soja à ração tenha contribuído para reduzir o impacto sobre os microrganismos que atuam na degradação dos componentes fibrosos.

Relacionando os dados de consumo de FDN e EE (Tabela 3) das dietas com OS e GS, verificou-se que a dieta com grão proporcionou menor consumo de EE e maior consumo de fibra, o que resultou em maior razão FDN/EE para a dieta com grão $(6,5)$ e menor para o óleo $(5,4)$. Assim, a maior digestibilidade da fibra na dieta com grão de soja pode ter sido ocasionada pela menor quantidade de óleo na digesta ruminal por unidade de fibra, associada à teoria de proteção parcial descrita por Van Soest (1994). De acordo com Jenkins (1993), os lipídios que normalmente inibem a fermentação e digestão causam menos efeitos quando o conteúdo de feno na dieta é alto.

Menor taxa de passagem de sólidos com o uso de grão de soja foi observada no experimento com cabras nãolactantes (Silva, 2005), o que colabora para justificar a maior digestibilidade da fibra com o uso desta forma de suplementação.

A suplementação com óleo na forma de SC proporcionou proteção semelhante na digestibilidade da fibra. Neste caso específico, é possível que o perfil de ácidos graxos no produto comercial, com maior participação de componentes saturados (Silva, 2005) considerados menos tóxicos aos microrganismos fibrolíticos tenha contribuído para a não-alteração da digestibilidade da fibra.

O nível de inclusão de EE nas dietas foi em torno de 4,5\%, próximo do limite máximo de inclusão de lipídios em dietas para ruminantes. No entanto, apesar do elevado consumo (Tabela 3), os valores de digestibilidade do EE indicam que os caprinos digeriram eficientemente este componente nutricional. Outro aspecto a ser considerado refere-se à grande quantidade de ácidos graxos insaturados, resultante da suplementação, justificando os elevados coeficientes de digestibilidade do EE.

A digestibilidade dos carboidratos totais foi afetada pela suplementação lipídica, refletindo as alterações na digestibilidade da fração fibrosa, como no caso do óleo de soja, ou da fração de CNF, observada com a adição de grão de soja à dieta. É possível que o maior tempo necessário para a redução das partículas do grão de soja tenha reflexo sobre a ação de microrganismos, com redução na digestibilidade dos $\mathrm{CNF}$, afetando o sincronismo entre as fontes de energia e proteína.

As repostas em produção e composição do leite são apresentadas na Tabela 5 .

Foram registradas diferenças significativas na produção de leite entre os tratamentos (Tabela 5). O teste de média não acusou diferenças entre as fontes de suplementação, mas a adição de grão de soja à ração contribuiu para a redução na produção de leite em relação ao tratamento controle, de forma semelhante ao observado para as produções de gordura e proteína. $\mathrm{O}$ uso dos suplementos promoveu redução na produção de lactose, mas não alterou a concentração dos constituintes lácteos.

Carvalho et al. (2006), avaliando níveis de fibra em dietas para cabras leiteiras do mesmo rebanho, obtiveram concentração de gordura de 3,25\% em animais com maior 
Tabela 5 - Efeito da suplementação lipídica sobre a produção e composição do leite de cabras Table 5 - Effect of fat supplements on mild yield and milk composition in lactating dairy goats

\begin{tabular}{|c|c|c|c|c|c|}
\hline \multirow[t]{3}{*}{$\begin{array}{l}\text { Item } \\
\text { Item }\end{array}$} & \multicolumn{4}{|c|}{$\begin{array}{c}\text { Dieta } \\
\text { Diet }\end{array}$} & \multirow[t]{3}{*}{$\mathrm{CV}$} \\
\hline & $\mathrm{C}$ & OS & $\mathrm{SC}$ & GS & \\
\hline & $C$ & SO & $C S$ & $W S$ & \\
\hline \multicolumn{6}{|l|}{ Produção (Production) } \\
\hline Leite (kg/d) (Milk, kg/day) & $2,24^{\mathrm{a}}$ & $1,77^{\mathrm{ab}}$ & $1,85^{\mathrm{ab}}$ & $1,52^{\mathrm{b}}$ & 25,66 \\
\hline Gordura (g/animal/d) (Fat, g/animal/day) & $90,74^{\mathrm{a}}$ & $74,89^{a b}$ & $76,45^{a b}$ & $57,06^{\mathrm{b}}$ & 27,57 \\
\hline Proteína (g/animal/d) (Protein, g/animal/day) & $70,78^{a}$ & $59,33^{\mathrm{ab}}$ & $61,39^{a b}$ & $50,70^{\mathrm{b}}$ & 23,25 \\
\hline Lactose $(\mathrm{g} / \mathrm{d})$ (Lactose, g/day) & $98,70^{\mathrm{a}}$ & $74,54^{\mathrm{b}}$ & $78,81^{\mathrm{b}}$ & $64,13^{\mathrm{b}}$ & 27,02 \\
\hline \multicolumn{6}{|l|}{ Composição (Composition) } \\
\hline Gordura $(\%)($ Fat, \%) & 4,04 & 4,11 & 4,13 & 3,65 & 14,75 \\
\hline Proteína (\%) (Protein, \%) & 3,17 & 3,41 & 3,35 & 3,38 & 8,14 \\
\hline Lactose $(\%)$ (Lactose, \%) & 4,38 & 4,20 & 4,26 & 4,15 & 7,42 \\
\hline
\end{tabular}

Médias na linha seguidas de letras distintas diferem a $5 \%$ de probabilidade pelo teste SNK.

$\mathrm{C}=$ controle; $\mathrm{OS}$ = óleo de soja; $\mathrm{SC}$ = sais de cálcio; $\mathrm{GS}$ = grão de soja.

Means in a row followed by different letters differ at $5 \%$ of probability by SNK test.

$C=$ control; $S O=$ soybean oil; $C S=$ calcium salts; $W S=$ whole soybean .

potencial para produção de leite $(3,91 \mathrm{~kg})$. Os menores níveis de produção das cabras podem ter contribuído para o maior valor percentual de gordura em relação aos obtidos em pesquisa anterior.

De acordo com o NRC (2001), a influência da suplementação lipídica na porcentagem de gordura do leite é variável e depende de sua composição e da quantidade fornecida. De forma geral, as gorduras encapsuladas, como os SC e as gorduras saturadas, aumentam ou não têm efeito sobre a concentração de gordura do leite (Sutton, 1989). À medida que a quantidade de ácidos graxos insaturados (livres ou esterificados) aumenta, é maior a probabilidade de diminuir a porcentagem de gordura do leite, caso exista biohidrogenação parcial da gordura. Outro aspecto a ser considerado é que, existindo intensa biohidrogenação, o perfil de ácidos graxos terá maior participação de ácidos saturados, o que poderá reduzir sua disponibilidade no intestino.

A captura de alguns ácidos graxos pré-formados (CLA trans-10 cis-12 e CLA trans-8 cis-10) também pode inibir a síntese da gordura do leite, por reduzir a atividade e/ou expressão de genes que codificam importantes enzimas envolvidas na captura, síntese e dessaturação dos ácidos graxos na glândula mamária (Bauman \& Griinari, 2001). No entanto, em cabras, Chilliard et al. (2003) sugeriram que a maior taxa de passagem da digesta nesta espécie pode diminuir os efeitos dos suplementos lipídicos sobre os fatores ruminais que reduziriam a lipogênese na glândula mamária, sendo esperado, portanto, aumento dos teores de gordura com a suplementação lipídica.

Apesar dessas observações, outros resultados comprovam que os efeitos da suplementação lipídica no desempenho de cabras ainda não estão elucidados. Cenkvàri et al. (2005), em estudo com caprinos, testaram a suplementação com SC de óleo de linhaça e verificaram que o conteúdo de gordura foi reduzido em algumas semanas ao longo do experimento.

A produção de lactose $(\mathrm{kg} / \mathrm{d})$ reduziu quando houve suplementação lipídica. É possível que a substituição de carboidratos não-fibrosos por lipídios a $4,5 \%$ possa ter contribuído para reduzir a produção de propionato, importante precursor gliconeogênico, contribuindo para menor disponibilidade de lactose na glândula mamária.

Constam na Tabela 6 os valores referentes ao consumo de energia e às eficiências bruta e líquida de utilização da energia para produção de leite.

Menores consumos de energia foram observados com a adição de óleo e de grão de soja, sendo numericamente inferior para o grão de soja. Os resultados apresentam o mesmo comportamento observado para o consumo de MS, o que confirma a inexistência de alguma llimitação física decorrente da presença de fibra.

Na avaliação da magnitude das respostas em produção de leite utilizando-se a medida de eficiências bruta de utilização da EM consumida, não foram observadas diferenças entre tratamentos.

Os dados foram também analisados considerando-se a estimativa da eficiência líquida, recomendada por Baldwin \& Smith (1983) por ser mais informativa que a eficiência bruta, por não incluir gastos com mantença. Utilizando-se esta medida, valores superiores para $\mathrm{k}_{1}$ foram obtidos para o tratamento com óleo de soja em relação àquele com sais de cálcio de ácidos graxos. A comparação entre os outros tratamentos não apontou diferenças significativas. 
É possível que os maiores valores encontrados para a eficiência de uso da energia das rações contendo óleo de soja tenham sido reflexo do potencial de resposta para a produção de leite pelas cabras, considerado mediano para rebanhos leiteiros, o que, provavelmente, contribuiu para uma ineficiência no uso da energia. Sabe-se que a produção de leite é dependente da quantidade total de energia consumida (Hussain et al., 1996). Os animais alimentados com as dietas controle ou com adição de sais de cálcio de ácidos graxos apresentaram maior consumo, sem redução nos valores de digestibilidade das rações. Entretanto, não tiveram resposta correspondente na produção de leite, o que, teoricamente, seria esperado, face à maior disponibilidade de energia. Sugere-se, portanto, que estudos semelhantes sejam avaliados utilizando-se animais de maior potencial para produção de leite.

Na Tabela 7 é apresentado o balanço dos compostos nitrogenados de cabras submetidas a dietas com diferentes formas de suplementação lipídica.

A suplementação lipídica não influenciou o consumo de nitrogênio e sua excreção nas fezes e no leite, mas reduziu a excreção urinária de nitrogênio pelos animais. O balanço e a retenção de $\mathrm{N}$ não foram influenciados pelos suplementos lipídicos (Tabela 7).

Tabela 6 - Efeito da suplementação lipídica sobre o consumo e a eficiência de utilização da energia em cabras lactantes

Table 6 - Effect of fat supplements on intake and efficiency of energy utilization in lactating dairy goats

\begin{tabular}{|c|c|c|c|c|c|}
\hline \multirow[t]{3}{*}{$\begin{array}{l}\text { Item } \\
\text { Item }\end{array}$} & \multicolumn{4}{|c|}{$\begin{array}{c}\text { Dieta } \\
\text { Diet }\end{array}$} & \multirow[t]{3}{*}{$\mathrm{CV}$} \\
\hline & C & OS & SC & GS & \\
\hline & $C$ & SO & $C S$ & $W S$ & \\
\hline \multicolumn{6}{|c|}{$\begin{array}{c}\text { Consumo de energia } \\
\text { Energy intake }\end{array}$} \\
\hline NDT $(\mathrm{kg} / \mathrm{d})(T N D, k g / d a y)^{1}$ & $1,88^{\mathrm{a}}$ & $1,57^{\mathrm{b}}$ & $1,85^{\mathrm{a}}$ & $1,46^{\mathrm{b}}$ & 12,59 \\
\hline \multirow[t]{2}{*}{$\mathrm{EL}_{2,1 \mathrm{X}}(\mathrm{Mcal} / \mathrm{d})\left(N E_{2,1 X}(\text { Mcal/day })^{2}\right.$} & $3,28^{\mathrm{a}}$ & $2,81^{b}$ & $3,30^{\mathrm{a}}$ & $2,64^{\mathrm{b}}$ & 12,04 \\
\hline & \multicolumn{4}{|c|}{$\begin{array}{c}\text { Eficiência de utilização da energia } \\
\text { Efficiency of energy utilization }\end{array}$} & \\
\hline $\mathrm{k}_{1}\left(k_{n}\right)^{3}$ & $0,54^{\mathrm{ab}}$ & $0,62^{\mathrm{a}}$ & $0,48^{\mathrm{b}}$ & $0,53^{\mathrm{ab}}$ & 19,98 \\
\hline $\mathrm{k}_{\mathrm{m}+\mathrm{p}} 4$ & 0,64 & 0,68 & 0,62 & 0,65 & 7,91 \\
\hline
\end{tabular}

Médias na linha seguidas de letras distintas diferem a $5 \%$ de probabilidade pelo teste SNK.

$\mathrm{C}=$ controle; $\mathrm{OS}$ = óleo de soja; $\mathrm{SC}$ = sais de cálcio; $\mathrm{GS}$ = grão de soja.

${ }^{1}$ Nutrientes digestíveis totais; ${ }^{2}$ Energia líquida de lactação; ${ }^{3}$ Eficiência líquida de utilização da energia metabolizável; ${ }^{4}$ Eficiência bruta da utilização da energia metabolizável.

Means in a row followed by different letters differ at $5 \%$ of probability by SNK test.

$C=$ control; $S O=$ soybean oil; $C S=$ calcium salts; $W S=$ whole soybean .

${ }^{1}$ Total digestible nutrients, ${ }^{2}$ Net energy; ${ }^{3}$ Net efficiency of utilization of metabolizable energy $;{ }^{4}$ Crude efficiency of utilization of metabolizable energy

Tabela 7 - Efeito da suplementação lipídica no balanço dos compostos nitrogenados em cabras lactantes Table 7 - Effect of fat supplements on nitrogen balance in lactating dairy goats

\begin{tabular}{|c|c|c|c|c|c|}
\hline \multirow[t]{3}{*}{$\begin{array}{l}\text { Item } \\
\text { Item }\end{array}$} & \multicolumn{4}{|c|}{$\begin{array}{c}\text { Dieta } \\
\text { Diet }\end{array}$} & \multirow[t]{3}{*}{$\mathrm{CV}$} \\
\hline & $\mathrm{C}$ & OS & SC & GS & \\
\hline & $C$ & SO & $C S$ & $W S$ & \\
\hline & \multicolumn{4}{|c|}{ g/dia (g/day) } & \\
\hline $\mathrm{N}$ consumido ( $N$ intake) & 51,59 & 41,18 & 44,30 & 41,34 & 14,49 \\
\hline $\mathrm{N}$ fezes $($ Fecal $N)$ & 8,43 & 9,36 & 9,59 & 9,45 & 21,52 \\
\hline $\mathrm{N}$ urina (Urinary $N$ ) & $24,67^{\mathrm{a}}$ & $16,52^{\mathrm{b}}$ & $18,20^{\mathrm{b}}$ & $19,54^{\mathrm{b}}$ & 18,69 \\
\hline $\mathrm{N}$ leite $(\operatorname{Milk} N)$ & 8,53 & 8,08 & 6,85 & 7,33 & 35,57 \\
\hline Balanço $\mathrm{N}$ ( $N$ balance $)$ & 9,96 & 7,23 & 9,66 & 5,01 & 46,84 \\
\hline $\operatorname{NEB}(B E N)^{1}$ & 7,16 & 7,99 & 7,67 & 7,70 & 9,60 \\
\hline $\mathrm{N}$ retido (Retained $N$ ) & 2,80 & $-0,76$ & 1,99 & $-2,69$ & 1279,9 \\
\hline
\end{tabular}

Médias na linha seguidas de letras distintas diferem a $5 \%$ de probabilidade pelo teste SNK.

$\mathrm{C}=$ controle; $\mathrm{OS}$ = óleo de soja; $\mathrm{SC}$ = sais de cálcio; $\mathrm{GS}$ = grão de soja.

${ }^{1} \mathrm{NEB}=$ nitrogênio endógeno basal (AFRC, 1993).

Means in a row followed by different letters differ at $5 \%$ of probability by SNK test.

$C=$ control; $S O=$ soybean oil $; C S=$ calcium salts $; W S=$ whole soybean .

${ }^{1}$ Basal endogenous nitrogen (AFRC, 1993). 
Avaliando a excreção urinária como proporção da quantidade de nitrogênio consumida, verificaram-se valores de $48,47,40$ e $41 \%$ para os tratamentos controle, com grão de soja, óleo e SC, respectivamente. As altas excreções de nitrogênio observadas sugerem que a concentração de $17 \%$ de proteína utilizada neste experimento pode ter sido excessiva, gerando gastos metabólicos desnecessários.

O nitrogênio endógeno basal (NEB) representa a exigência de nitrogênio para manter as atividades metabólicas basais, como a renovação celular. De acordo com Riis (1983), a taxa de deposição de proteína aumenta até determinado nível com maior fornecimento de energia, proteína e outros nutrientes. Os mais altos consumos de energia foram observados com as dietas controle e SC. Assim, os maiores valores observados com essas dietas sugerem a possibilidade de maior aproveitamento dos nutrientes para deposição e renovação das proteínas teciduais, justificada pela análise da retenção de nitrogênio pelos animais, que seria a quantidade de $\mathrm{N}$ líquido disponível para ganho. Apesar de não diferirem estatisticamente e resultarem em coeficiente de variação extremamente alto, as dietas controle e com SC apresentaram valores positivos, revelando melhor eficiência de utilização do nitrogênio.

\section{Conclusões}

A forma de suplementação lipídica altera o consumo de MS e de nutrientes, com reflexos sobre a produção de leite e a eficiência de uso da energia disponível.

A digestibilidade da fibra é reduzida com a adição de óleo na forma livre e a digestibilidade de $\mathrm{CNF}$ diminui com a adição de grão de soja, reduzindo, conseqüentemente, a quantidade de energia disponível aos animais.

Os sais de cálcio de ácidos graxos são bons substitutos aos carboidratos fermentáveis quando o objetivo é elevar a concentração energética das dietas de cabras em lactação.

\section{Literatura Citada}

AGRICULTURAL AND FOOD RESEARCH COUNCIL - AFRC. Energy and protein requirements of ruminants. Wallingford: CAB international, 1993. 159p.

ALLEN, M.S. Effects of diet on short-term regulation of feed intake by lactating dairy cattle. Journal of Dairy Science, v.83, p.1598-1624, 2000

BALDWIN, R.L.; SMITH, N.E. Adaptation of metabolism to various conditions: milk production. In: RIIS, P.M. (Ed). Dynamic biochemistry of animal production. New York: Elsevier, 1983. p. 359-388

BATEMAN II, H.G.; JENKINS, T.C. Influence of soybean oil in high fiber diets fed to nonlactating cows on ruminal unsaturated fatty acids and nutrient digestibility. Journal of Dairy Science, v.81, p.2451-2458, 1998
BAUMAN, D.E. Regulation of nutrient partitioning during lactation: homeostasis and homeorhesis revisited. In: CRONJÉ, P.B. (Ed.) Ruminant physiology: digestion, metabolism, growth and reproduction. Oxon: CABI Publishing, 2000. p.311-328.

BAUMAN, D.E.; GRIINARI, J.M. Regulation and nutritional manipulation of milk fat: low-fat milk syndrome. Livestock Production Science, v.70, p.15-29, 2001

BRANCO, R.H. Avaliação da qualidade da fibra sobre a cinética ruminal, consumo e eficiência de utilização de nutrientes em cabras leiteiras. Viçosa, MG: Universidade Federal de Viçosa, 2005. 151p. Tese (Doutorado em Zootecnia) Universidade Federal de Viçosa. 2005.

CARVALHO, S.; RODRIGUES, M.T.; BRANCO, R.H. et al. Consumo de nutrientes, produção e composição do leite de cabras da raça Alpina alimentadas com dietas contendo diferentes teores de fibra. Revista Brasileira de Zootecnia, v.35, n.3, p.11541161, 2006 (supl.).

CENKVÀRI, É.; FEKETE, S.; FEBLE, H. et al. Investigation on the effects of Ca-soaps of oil linseed on rumen fermentation in sheep on milk composition of gotas. Journal of Animal Physiology an Animal Nutrition, v.89, p.172-178, 2005.

CHALUPA, W.; VECCHIARELLI, B.; ELSER, A.E. et al. Ruminal fermentation in vivo as influenced by long-chain fatty acids. Journal of Dairy Science, v.69, p.1293-1301, 1986.

CHELIKANI, P.K.; BELL, J.A.; KENNELLY, J.J. Effects of feeding or abomasal infusion of canola oil in Holstein cows. 1. Nutrient digestion and milk composition. Journal of Dairy Research, v.71, p.279-287, 2004.

CHILliARD, Y.; FERLAY, A.; ROUEL, J. et al. A review of nutritional and physiological factors affecting goat milk lipid synthesis and lipolysis. Journal of Dairy Science, v.86, p.1751-1770, 2003

DOREAU, M.; CHILLIARD, Y.; BAUCHART, D. et al. Influence of different fat supplement on digestibility and ruminal digestion in cows. Annales de Zootecnie, v.40, p.19-30, 1990.

ENJALBERT, F.; MONCOULON, R.; VERNAY, M. et al. Effects of different forms of polyunsaturated fatty acids on rumen fermentation and total nutrient digestibility of sheep fed prairie hay based diets. Small Ruminant Research, v.14, p.127-135, 1994.

HALL, M.B. Management strategies against ruminal acidosis. In: ANNUAL FLORIDA RUMINANT NUTRITION SYMPOSIUM, 10., 1999, Gainsville. Proceedings... Gainsville: 1999. p.104-113.

HUSSAIN, Q.; HAVREVOLL, Ø.; EIK, L.O. Effect of type of roughage on feed intake, milk yield and body condition of pregnant goats. Small Ruminant Research, v.22, p.131-139, 1996.

IKWUEGBU, O.A.; SUTTON, J.D. The effect of varying the amount of linseed oil supplementation on rumen metabolism in sheep. British Journal Nutrition, v.48, p.365-375, 1982.

JENKINS, T.C. Lipid metabolism in the rumen. Journal of Dairy Science, v.76, p.3851-3863, 1993.

JENKINS, T.C.; JENNY, B.F. Effect of hidrogenate fat on feed intake, nutrient digestion and lactation performance of dairy cows. Journal of Dairy Science, v.72, p.2316-2324, 1989.

LICITRA, G.; HERNANDEZ, T.M.; Van SOEST, P.J. Standardization of procedures for nitrogen fractionation of ruminants feeds. Animal Feed Science and Technology, v.57, p.347-358, 1996.

LUO, J.; GOETSCH, A.L.; NSAHLAI, I.V. et al. Maintenance energy requirements of goats: predictions based on observations of heat and recovered energy. Small Ruminant Research, v.53, p.221-230, 2004.

McDONALD, P. Evaluation of foods (D) protein. In: McDONALD, P.; EDWARDS, R.; GREENHALGH, J.F.D. (Eds.). Nutrition animal. 4.ed. Zaragoza: Acríbia, 1993. p.29-57.

MOE, P.W.; TYRRELL, H.F. Estimating metabolizable and net energy of feeds. In: INTERNATIONAL SUMPOSIUM ON FEED COMPOSITION, ANIMAL NUTRIENT REQUERIMENTS AN COMPUTERIZATION OF DIETS, 1977, Logan. Proceedings... Logan: 1977. p.232 
MOE, P.W.; FLATT, W.P.; TYRREL, H.F. Net energy value of feeds for lactation. Journal of Dairy Science, v.55, p.945, 1972.

MOREIRA, M.A. Programa de melhoramento genético da qualidade de óleo e proteína da soja desenvolvido na UFV. In: CONGRESSO BRASILEIRO DE SOJA, 1999, Londrina. Anais... Londrina: EMBRAPA SOJA, 1999. p.99-104.

NATIONAL RESEARCH COUNCIL - NRC. Nutrient requirements of goats. Washington, D.C.: National Academic Press, 1981. $91 \mathrm{p}$.

NATIONAL RESEARCH COUNCIL - NRC. Nutrient requirements of dairy cattle. 7.ed. Washington, D.C.: National Academic Press, 2001. 387p.

NICHOLSON, T.; OMER, S.A. The inhibitory effect of intestinal infusions of unsaturated long-chain fatty acids on forestomach motility of sheep. British Journal of Nutrition, v.50, p.141$149,1983$.

PALMQUIST, D.L. Influence of source and amount of dietary fat on digestibility in lactating cows. Journal of Dairy Science, v.74, n.1, p.1354-1360,1991.

PALMQUIST, D.L.; JENKINS, T.C. Fat in lactation rations: review. Journal of Dairy Science, v.63, p.1-14, 1980

PEREIRA, J.R.A.; ROSSI JR., P. Manual prático de avaliação de alimentos. Piracicaba: Fundação de Estudos Agrários Luiz de Queiroz, 1995. 25p.

PEREZ ALBA, L.M.; DE SOUSA CAVALCANTI, S.; PEREZ HERNANDEZ, M. et al. Calcium soaps of olive fatty acids in the diets of Manchega dairy ewes: effects on digestibility and production. Journal of Dairy Science, v.80, p.3316-3324, 1997

RIIS, P.M. The pools of tissue constituents and products: proteins. In: RIIS, P.M. (Ed). Dynamic biochemistry of animal production. New York: Elsevier, 1983. p.75-108.
STATISTICAL ANALYSIS SYSTEM - SAS. User's guide: statistics. Version 8.0. Cary: 1999. (CD-ROM).

SCHNEIDER, P.; SKLAN, D.; CHALUPA, P. et al. Feeding calcium salts of fatty acids to lactating cows. Journal of Dairy Science, v.71, p.2143-2150, 1988 .

SILVA, M.M.C. Suplementação de lipídios em dietas para cabras leiteiras. Viçosa, MG: Universidade Federal de Viçosa, 2005. 108p. Tese (Doutorado em Zootecnia) - Universidade Federal de Viçosa. 2005.

SILVA, D.J; QUEIROZ, A.C. Análise de alimentos (métodos químicos e biológicos). Viçosa, MG: Editora UFV, 2002. 235p.

SNIFFEN, C.J.; O'CONNOR, J.D.; Van SOEST, P.J. A net carbohydrate and protein system for evaluating cattle diets: II. Carbohydrate and protein availability. Journal of Animal Science, v.70, p.3562-3577, 1992.

SUTTON, J.D. Altering milk composition by feeding. Journal of Dairy Science, v.72, p.2801-2814, 1989.

Van SOEST, P.J. Nutritional ecology of the ruminant. 2.ed. Ithaca: Comstock, 1994. 476p.

Van SOEST, P.J.; ROBERTSON, J.B.; LEWIS, B.A. Methods of dietary fiber, neutral detergent fiber, and nonstarch polysaccharides in relation to animal nutrition. Journal of Animal Science, v.74, p.3583-3597, 1991.

WETTSTEIN H.R.; MACHMÜLLER A.; KREUZER M. Effect of raw and modified canola lecithins compared to canola oil, canola seed and soy lecithin on ruminal fermentation measured with rumen simulation technique. Animal Feed Science Technology, v.85, p.53-169, 2000 